\title{
The Relationship Between Childhood BMI and Adult Serum Cholesterol, LDL, and Ankle Brachial Index
}

\author{
M.E. Sundaram; R.L. Berg; C. Economos; and L.A. Coleman
}

\begin{abstract}
Objective: Effects of childhood overweight may persist into adulthood. We assessed the effect of childhood overweight on cardiovascular disease high risk factor levels in the same participants as adults, after controlling for adult body mass index (BMI) status.

Design: A subset of participants in an observational study (Heartwatch) were contacted approximately 26-27 years after initial enrollment to participate in a follow-up study on the long-term effects of childhood overweight. During follow-up, BMI, waist:hip circumference (WHC), blood pressure (BP), serum lipids, and ankle brachial index $(\mathrm{ABI})$ were measured; additional $\mathrm{BMI}$ measures throughout childhood were obtained as available from the electronic medical record. Primary outcomes were ABI and serum low density lipoprotein (LDL).
\end{abstract}

Setting: The 1982 Heartwatch study was conducted with children participants living in Marshfield, Wisconsin; follow-up included original participants who were re-contacted and agreed to be enrolled.

Participants: Participants were a stratified random sample of eligible participants in the original 1982 Heartwatch study. Of the original 3106 participants, 647 adult participants completed follow-up exams.

Results: Among males with $1982 \mathrm{BMI} \geq 85^{\text {th }}$ percentile, adult $\mathrm{BMI}, \mathrm{WHC}$, (both $\left.P \leq 0.00 \mathrm{I}\right), \mathrm{ABI}(P=$ $0.00 \mathrm{I})$, total cholesterol $(P=0.0 \mathrm{I})$, $\mathrm{LDL}(P=0.003)$ and BP $(P<0.02)$ were higher in 2008-2009 as compared to males with $1982 \mathrm{BMI}<85^{\text {th }}$ percentile. Among females, BMI, BP and WHC (all $P<0.00 \mathrm{I}$ ) were higher in 2008-2009. BMI in 1982 and 2008-2009 were correlated $[r=0.56$ (males); 0.58 (females), $P<0.00 \mathrm{I}$ ]. 2008-2009 BMI was more strongly correlated with 2008-2009 measures of ABI $(r=0.16, P=0.006$, males) and high LDL $[r=0.18, P=0.002$ (males); $r=0.1 \mathrm{I}, P=0.046$ (females)]. $1982 \mathrm{BMI}$ was not independently associated with $\mathrm{ABI}$ or $\mathrm{LDL}$ after adjusting for adult BMI.

Conclusion: In a cohort studying childhood and adult overweight, childhood BMI was associated with health outcomes relating to cardiovascular disease in adulthood. However, childhood BMI was not independently related to $L D L-C$ or $A B I$ levels in adulthood after accounting for adult $B M I$. Longitudinal measurements of $\mathrm{BMI}$ and other health risk factors were not found to improve accuracy of models for high cardiovascular disease risk factor levels.

Keywords: Childhood overweight, BMI, Cardiovascular disease

$\mathrm{T}$ he prevalence of overweight and obesity among children, adolescents, and adults in the U.S. has increased dramatically over the past several decades ${ }^{1}$ but may be reaching a plateau. ${ }^{2}$ Child and adolescent overweight tracks to adult obesity, ${ }^{3-5}$ a condition associated with an increased incidence of disease, including hypertension, cardiovascular disease (CVD), type 2 diabetes mellitus, gallstones, sleep apnea, and some cancers. ${ }^{6}$ However, it is not clear whether these conditions are specifically related to overweight during childhood, adolescence, or adulthood; or whether a
Corresponding Author: Maria E. Sundaram; Department of Environmental
Health Sciences; University of Minnesota; 1260 Mayo Building; 420 Delaware

Street SE; Minneapolis, MN 55455; Email: maria.e.sundaram@gmail.com
Received: April 26, 2013

Revised: August 12, 2013

Accepted: September 4, 2013

doi: $10.3121 / \mathrm{cmr} .2013 .1172$

Grant Support: This work was
supported by
IR03HD0544I2-0IA2 NICHD
3R03HD0544I2-02SI.


cumulative risk burden exists where the longer an individual is overweight, the greater their risk of disease.

Many studies that have examined the impact of obesity occurring at different times during the lifespan have yielded conflicting results, $, 4,7$ and there is some discussion regarding whether certain periods of time contribute more risk later in life than other periods of time, or whether risk is contributed in a more linear fashion. ${ }^{8}$ Factors such as age when weight status was assessed during youth, availability of longitudinal data, confounding factors, and outcome measures (serum lipids, carotid intima media thickness [IMT] or ankle brachial index $[\mathrm{ABI}]$, for example), may contribute to disparate findings. An alternative to using IMT to predict pre-clinical $\mathrm{CVD}, \mathrm{ABI}$ is a low-cost, non-invasive tool that acts as a surrogate for the presence of CVD risk by detecting arterial occlusions. It is inversely associated with the degree of subclinical atherosclerosis determined by IMT $^{9-11}$ and several large-scale longitudinal studies have shown that low ABI is associated with a marked increase in CVD risk (reviewed by Caruana et $\mathrm{al}^{12}$ ).

We conducted a follow-up study to determine the relationship between childhood weight status and CVD risk during middle adulthood among participants in a 1982 study on heart disease (Heartwatch). We tested the hypothesis that body mass index $(\mathrm{BMI}) \geq 85^{\text {th }}$ percentile during youth is associated with increased CVD risk measured by ABI and serum lipids in adulthood, after controlling for the effect of adult weight status on disease.

\section{Methods and Procedures}

Study Design and Participants

We conducted a follow-up study of the original Heartwatch Study, conducted in 1982 in Marshfield, Wisconsin. ${ }^{13}$ Marshfield is a rural community with a relatively stable population, served by a single major medical center, the Marshfield Clinic. Briefly, all students in public and private schools in Marshfield, WI in 1982 were invited to participate in a cross-sectional cardiovascular risk factor screening study. Participating children/adolescents had height, weight, and fasting serum lipids measured at school; questionnaires were administered covering demographic characteristics, medical history, family history and diet. The original study included 3106 children aged 5-15 years. ${ }^{13}$ Beginning before the original study, outpatient health care provided to Heartwatch study participants at Marshfield Clinic and inpatient data provided at St. Joseph's Hospital (the only hospital in the immediate area) have been recorded in a combined medical record which has followed participants consistently throughout the intervening period. Most of these historical data were available electronically for this study (diagnoses since the creation of the medical record to the present, laboratory results 1985 to present, height and weight 1994 to present). BMI results, for example, were obtained as available from the electronic medical record (EMR) from 1994-2010, with a median of 13 results available per subject (range 1-139).
The follow-up enrollment period occurred between April 2008 and December 2009. Based on a feasibility survey, researchers estimated that, of individuals still living and whose addresses were known, approximately 1030 subjects with baseline BMI $<85^{\text {th }}$ percentile and 220 subjects with baseline $\mathrm{BMI}>85^{\text {th }}$ percentile would be available for participation. To improve statistical power for identifying associations with a minimum number of subjects, all individuals with $\mathrm{BMI}>85^{\text {th }}$ percentile were approached to be enrolled, and a stratified random sample (initially matched $2: 1$ by gender and 1982 age groups 5-8, 9-11 and $12-16$ years) of former participants whose BMI was $\leq 85^{\text {th }}$ percentile were also approached for enrollment. Numbers in the matched sample were subsequently increased to offset enrollment limitations in the BMI $>85^{\text {th }}$ percentile group. The study procedures were reviewed and approved by the Marshfield Clinic Institutional Review Board. All participants provided written consent prior to enrollment.

\section{Recruitment and Enrollment}

A public affairs campaign with radio and newspaper press releases was used to promote regional public awareness of the follow-up study. Telephone numbers for 3075 Heartwatch participants (99\%) were obtained from the Marshfield Clinic EMR. Up to five calls were made by trained personnel utilizing telephone scripts to locate the study participant and schedule an appointment for the follow-up examination. Weekend, evening, and holiday visits were scheduled as needed. All visits took place at Marshfield Clinic.

\section{Specimen Collection and Handling Procedures}

- Anthropometrics - Height was determined using a stadiometer and weight was measured using a beam scale, according to standard methods. ${ }^{14}$ Measurements were made in duplicate with the subject wearing light clothing (no shoes). Weight was recorded to the nearest $1 / 4$ pound; BMI was calculated $\left(\mathrm{kg} / \mathrm{m}^{2}\right)$ and classified according to National Institutes of Health (NIH) and Centers for Disease Control and Prevention (CDC) recommendations (underweight $<18.5$, normal weight 18.5-24.9, overweight 25-29.9, obesity class $1,30-34.9$, and obesity class 2 , 35-39.9). ${ }^{15,16}$ Study staff measured waist and hip circumferences according to standard procedures. ${ }^{17}$ The mean of two measurements was determined for each measurement site. Gender-specific cut-offs from the NIH were used to classify the point at which waist circumference was associated with increased disease risk: for males, $>$ 40 inches $(102 \mathrm{~cm})$ and for females, $>35$ inches $(88$ $\mathrm{cm}){ }^{15}$ Waist:hip ratio was calculated and used as a measure of fat distribution.

- Blood pressure - Blood pressure (BP) was measured using standard procedures from the Antihypertensive and Lipid-Lowering Treatment to Prevent Heart Attack Trial (ALLHAT). ${ }^{18}$ Three BP measurements were recorded after the subject had been sitting at rest for 5 minutes. The average of the last two measurements was used for analysis. Hypertension was defined as BP $>140 / 90 .{ }^{19}$ 
Table 1: Demographic characteristics of participants.

\begin{tabular}{|c|c|c|c|c|}
\hline \multirow[b]{2}{*}{ Characteristic } & \multicolumn{2}{|c|}{ Male } & \multicolumn{2}{|c|}{ Female } \\
\hline & $\begin{array}{c}1982 \mathrm{BMI} \\
\geq 85^{\text {th }} \text { percentile }\end{array}$ & $\begin{array}{c}1982 \mathrm{BMI} \\
<85^{\text {th }} \text { percentile }\end{array}$ & $\begin{array}{c}1982 \mathrm{BMI} \\
\geq 85^{\text {th }} \text { percentile }\end{array}$ & $\begin{array}{c}1982 \mathrm{BMI} \\
<85^{\text {th }} \text { percentile }\end{array}$ \\
\hline$N$ & 67 & 236 & 86 & 258 \\
\hline Age (years) & $38(36,39)$ & $38(36,40)$ & $37(35,39)$ & $37(35,39)$ \\
\hline BMI $\left(\mathrm{kg} / \mathrm{m}^{2}\right)$ & $33(29,39)^{\star *}$ & $27(24,30)$ & $34(27,39) \dagger$ & $25(22,29)$ \\
\hline Systolic BP (mmHg) & $120(111,128)^{\star *}$ & $116(109,123)$ & $111(104,121) \dagger$ & $106(99,114)$ \\
\hline Diastolic BP (mmHg) & $82(75,87)^{\star *}$ & $78(73,83)$ & $75(69,81) \dagger$ & $71(66,77)$ \\
\hline Waist (cm) & $110(98,125)^{\star *}$ & $94(88,102)$ & $102(91,119) \dagger$ & $84(75,94)$ \\
\hline Hip (cm) & $113(103,124)^{\star \star}$ & $103(97,107)$ & $117(106,129) \dagger$ & $103(96,110)$ \\
\hline ABI & $1.14(1.11,1.18)^{* *}$ & $1.12(1.09,1.16)$ & $1.13(1.09,1.15)$ & $1.11(1.07,1.16)$ \\
\hline Total cholesterol (mg/dL)‡ & $203(175,223)^{*}$ & $186(161,209)$ & $175(161,202)$ & $175(157,194)$ \\
\hline HDL cholesterol (mg/dL) & $39(32,44)$ & $40(33,47)$ & $49(42,59)$ & $49(42,61)$ \\
\hline LDL cholesterol (mg/dL) & $133(114,149)^{\star *}$ & $117(98,140)$ & $103(89,121)$ & $104(88,123)$ \\
\hline Triglycerides (mg/dL) & $122(87,191)$ & $110(71,179)$ & $89(55,142)$ & $76(53,113)$ \\
\hline
\end{tabular}

Values shown are median (25 th percentile, $75^{\text {th }}$ percentile), as measured in 2008-2009. $P$ values indicated by asterisks are calculated from Wilcoxon rank-sum tests. ${ }^{*} P<0.05,{ }^{* *} P<0.01$ among males with $\mathrm{BMI} \geq 85^{\text {th }}$ percentile compared to males with $\mathrm{BMI}<85^{\text {th }}$ percentile

$\dagger P<0.01$ among females with $\mathrm{BMI} \geq 85^{\text {th }}$ percentile compared to females with $\mathrm{BMI}<85^{\text {th }}$ percentile.

FFor serum lipid data, $\mathrm{n}=59$ for $\mathrm{BMI} \geq 85^{\text {th }}$ percentile and $\mathrm{n}=216$ for $\mathrm{BMI}<85^{\text {th }}$ percentile.

$\mathrm{BMI}=$ body mass index; $\mathrm{ABI}=$ ankle brachial index; $\mathrm{HDL}=$ high density liproprotein; $\mathrm{LDL}=$ low density liproprotein; $\mathrm{BP}=$ blood pressure.

- Ankle-brachial index - After subjects rested supine for 5 minutes, a hand-held Doppler probe (Nicolet PocketDop II, Nicolet Vascular, Golden CO) was used to measure systolic pressures in the right brachial artery, right dorsalis pedis and posterior tibial arteries, and the left brachial artery. ${ }^{18}$ Pressures were measured twice, and averaged for each limb. The ABI was calculated by dividing the minimum leg pressure by the maximum brachial pressure. ${ }^{20}$ An ABI value below 0.90 was considered abnormal. ${ }^{21}$ Normal ABI was defined as 1.101.29 , low-normal as $1.00-1.09$, and borderline normal as 0.90-0.99. ${ }^{21}$ No participants had an ABI above 1.29.

- Serum lipid and lipoproteins - A 3-mL fasting (14-hour) blood sample was obtained for measurement of serum lipids and lipoproteins (total, HDL, LDL cholesterol; triglyceride level). Lipids were analyzed according to standard methods by Marshfield Laboratories. ${ }^{22}$

- Questionnaire - A self-administered questionnaire containing basic demographic and health status information was sent to subjects for completion prior to their clinical examination. This questionnaire included questions about smoking ("During your life, have you smoked at least 100 cigarettes?") and self-reported diseases ("Do you have a history of any of the following health conditions: asthma, blood clots, cancer, depression, diabetes, gall bladder disease, heart disease, high cholesterol level, high blood pressure, obesity, osteoarthritis, polycystic ovary disease, rheumatoid arthritis, sleep apnea, other?"). Study staff reviewed the questionnaire for completeness during the follow-up visit.

- Historical measures - Health history information, including height and weight, was abstracted from the EMR for any participant who received at least some medical care at the Marshfield Clinic.

\section{Analytic Approach}

Standard descriptive statistics were used to characterize the follow-up study and to assess the extent to which the followup study participants were representative of the original study population. The primary exposure variable was BMI z-score; child and adult percentiles were analyzed as continuous variables by normalizing BMI results to age- and sex-specific z-scores, using data from the National Health and Nutrition Examination Survey (NHANES). For children, the normalization used the United States Growth Charts smoothed percentile curves based on the May 30, 2000 release. For adults, tabled NHANES data from the same release were smoothed using the LMS method for creation of the z-scores. ${ }^{23,24}$ Categorical variables for child and adult weight status were created based on standard definitions. ${ }^{25}$ Primary outcome variables used as measures of high cardiovascular disease risk were ABI and serum LDL. Thirty-seven subjects with medically-treated dyslipidemia were excluded from analyses of LDL. Dichotomous variables were defined as abnormal ABI $(<0.9$, yes $/$ no) and dyslipidemia (as defined above, yes/no). The primary analyses were based on analysis 


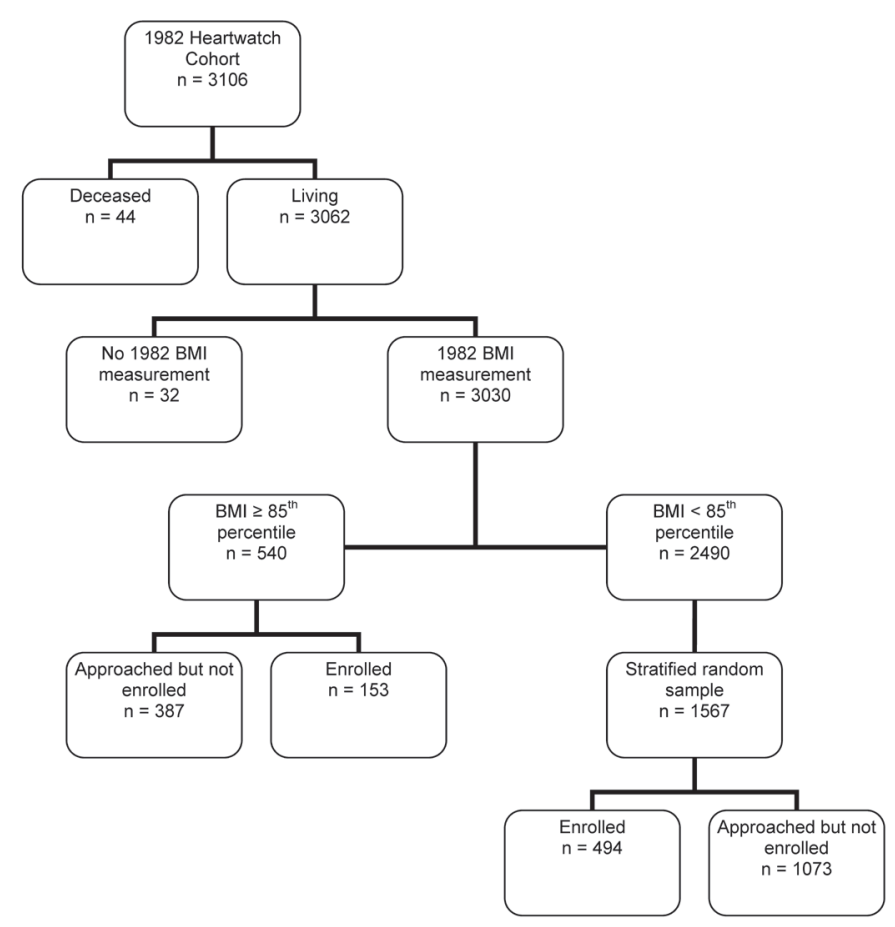

Figure 1. Participant cohort diagram. Of the original 3106 Heartwatch participants, 44 were deceased and 32 had no 1982 BMI measurement on file during recruitment in 2008. A stratified random sample was taken of participants with 1982 $\mathrm{BMI} \geq$ and $<85^{\text {th }}$ percentile so as to match the BMI proportions of the original Heartwatch study.

of variance (ANOVA) for general linear models. Each primary outcome was analyzed for association with the baseline (child/adolescent) and follow-up (adult) BMI z-scores, with gender, age, and smoking (ever/never smoked 100 cigarettes) as covariates in the models. All analyses were performed using SAS Version 9.2 (SAS Institute, Cary, NC), and a $P$ value $<0.05$ was considered statistically significant.

\section{Results}

Of 3062 still-living 1982 Heartwatch study participants, a total of 540 with $\mathrm{BMI} \geq 85^{\text {th }}$ percentile, and a total of 1567 with $\mathrm{BMI}<85^{\text {th }}$ percentile were approached to be enrolled. A total of 647 were enrolled in the follow-up study: 153 in the $1982 \mathrm{BMI} \geq 85^{\text {th }}$ percentile group, and 494 in the $1982 \mathrm{BMI}$ $<85^{\text {th }}$ percentile group (Figure 1). In both the original
Heartwatch study and the follow-up study, 44\% of the participants were male in the $\mathrm{BMI} \geq 85^{\text {th }}$ group and $48 \%$ were male in the BMI $<85^{\text {th }}$ group (Table 1). Overall age of participants was comparable between BMI groups in both study populations. BMI z-score, serum LDL, 2008-2009 systolic and diastolic BP, and waist:hip circumference ratio were all slightly lower on average in the $\mathrm{BMI}<85^{\text {th }}$ group compared to the $\mathrm{BMI} \geq 85^{\text {th }}$ group. There was a significant difference in calculated ABI between BMI groups for men, but not for women.

BMI z-score in 1982 was moderately correlated with BMI $\mathrm{Z}$-score in 2008-2009 in both men $(\mathrm{r}=0.57, P<0.001)$ and women $(\mathrm{r}=0.58, P<0.001)$ (Figure 2$)$. Children 9 years and younger when the original study was conducted $(n=238)$ showed a correlation of original/current BMI z-scores of 0.55 , while children 12 years and older $(\mathrm{n}=165)$ showed a correlation of 0.67 ( $P$ for difference in correlations $=0.05$ ). Levels of LDL in 1982 were associated with LDL levels in 2008-2009 (r = 0.44, $P<0.001)$.

Linear regression analysis revealed that neither the 1982 BMI Z-score nor smoking at least 100 cigarettes over a participant's lifetime were significantly related to continuous ABI score or serum LDL in models also including gender, age, and 20082009 BMI z-score (Tables 2 and 3). The 2008-2009 BMI Z-score was positively associated with increased ABI score and serum LDL in these models.

\section{Discussion}

Childhood BMI was not significantly associated with adult CVD risk factor levels measured by ABI and LDL after controlling for adult weight status in our population. However, childhood BMI tracked closely into adulthood, and this association limited our ability to determine effects of childhood BMI independent of adult BMI. These findings suggest that regardless of whether childhood BMI is independently associated with adult CVD risk factor levels, it is strongly related to adult weight status.

Our findings are supported by others who have suggested that adult obesity modifies the association between childhood adiposity and sub-clinical CVD assessed by IMT in adulthood. ${ }^{26-28}$ Freedman et al. compared childhood and adult

Table 3: Regression analysis of factors influencing serum LDL.

\begin{tabular}{lccc}
\hline Characteristic & $\begin{array}{c}\text { Parameter estimate } \\
(\boldsymbol{\beta})^{\mathbf{a}}\end{array}$ & Standard error & $\boldsymbol{P}$ value \\
\hline Male gender & 13.36 & 2.36 & $<0.0001$ \\
Age & 1.36 & 0.43 & $<0.01$ \\
1982 BMI z-score & -2.63 & 1.57 & 0.09 \\
2008-2009 BMl z-score & 5.87 & 1.55 & $<0.001$ \\
Smoked at least 100 cigarettes in lifetime & -0.49 & 2.39 & 0.84 \\
Intercept & 57.01 & 16.03 & $<0.001$ \\
\hline
\end{tabular}

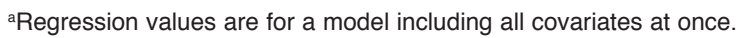


BMI for Heartwatch Cohort: Current vs. Original

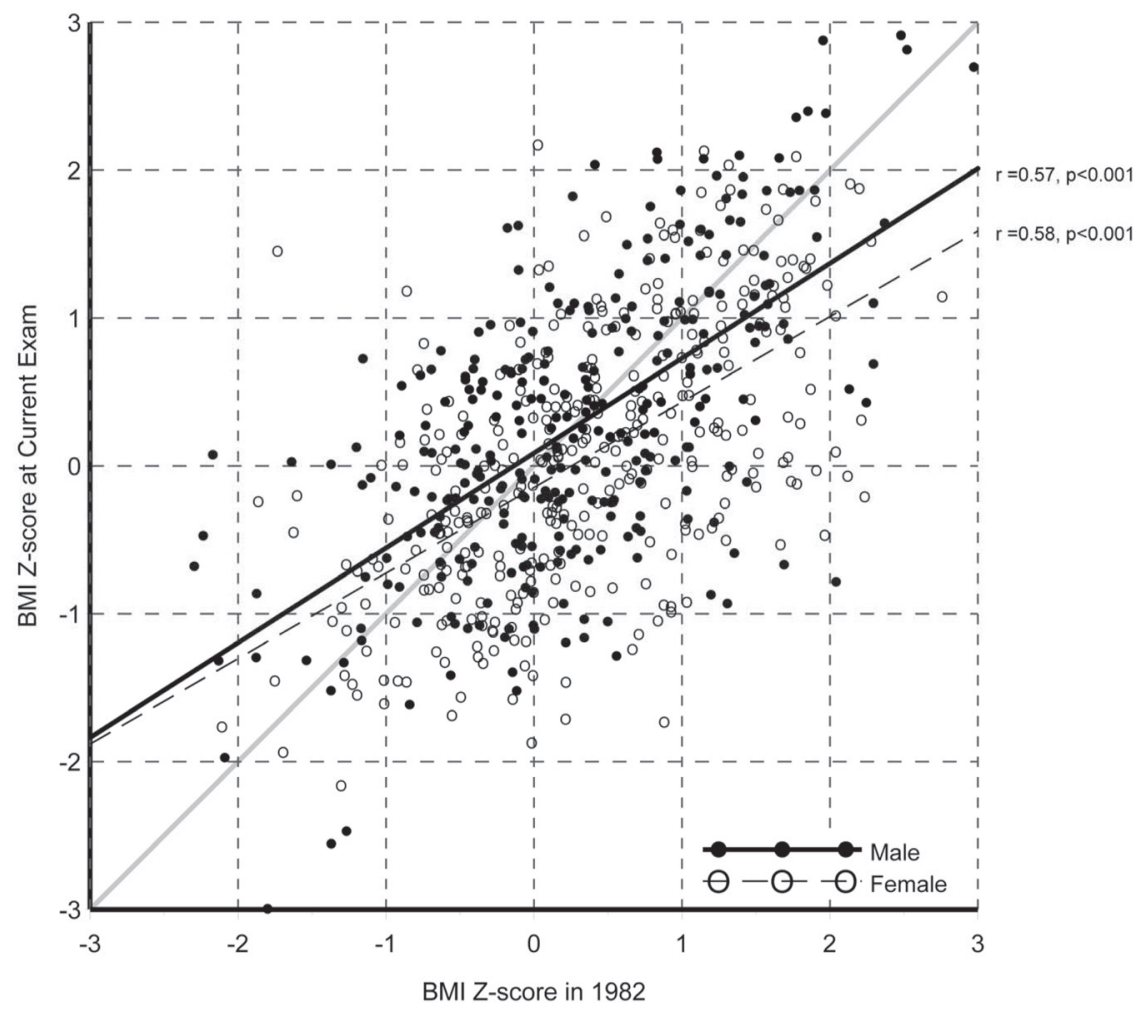

Figure 2. Correlation of childhood and adult BMI. After z-scores were assigned to each participant's childhood and adulthood BMI, these values were found to be tightly correlated with each other, both for men and for women. Pregnant women were not included in this analysis but are shown in the figure for reference. This model assumes a linear relationship between childhood and adult BMI. $R=$ Spearman rank correlation coefficient.

obesity as predictors of adult IMT in the Bogalusa Heart Study and found that adult obesity modified the association between childhood adiposity and IMT. ${ }^{7}$ Similarly, Li et al. found that higher childhood BMI predicted thicker adult IMT, but that the cumulative burden of risk factors from childhood to adulthood provided no additional predictive value for thicker adult IMT. ${ }^{5}$ Finally, both Lloyd et al. and Juonala et al. found that although obesity and overweight in childhood and adulthood are related, people who were overweight or obese during childhood but nonobese as adults had lowered risk compared to obese adults. ${ }^{27,28}$ However, in the Cardiovascular Risk in Young Finns Study, Raitakari et al. provided evidence that CVD risk factors in 12-18 year-olds, including increased BMI, were independently associated with adult IMT, even after adjusting for adult risk factors. ${ }^{4}$ However, risk factors for CVD measured during childhood (ages 3-9 yrs) were either weakly (in adult men) or not at all (in adult women) associated with IMT.

The hypothesis that BMI tracks from childhood to adulthood is widely supported in the literature; Juhola et al. observed in the Cardiovascular Risk in Young Finns study ${ }^{3}$ and Whitaker et al. observed in a large observational cohort in the United States $^{29}$ that adolescent BMI is closely related to adulthood BMI, and reviews by Lloyd et al. ${ }^{27}$ and Serdula et al. ${ }^{30}$ corroborate these findings. We were able to add to the existing knowledge base by examining the contribution of obesity over time to adult disease due to the extensive EMR system at the Marshfield Clinic, and to the stability of our cohort. ${ }^{31,32}$ Our finding of non-significant additional predictive value related to the degree of overweight over time is supported by Li et al, ${ }^{5}$ who found that the cumulative burden of risk factors from childhood to adulthood provided no additional predictive value for disease.

This study used ABI to determine higher risk for cardiovascular disease. Ankle brachial index has been validated as a tool to determine CVD risk $^{33}$ and has been used widely to study CVD risk in other populations..$^{20,34-38}$ This study also used childhood BMI z-scores calculated from CDC growth charts ${ }^{39}$ to stratify participants. Others have suggested that earlier CDC growth charts did not account for the rapid rise in childhood BMI during the 1980s, and that confounders such as level of physical activity and quality of diet are apt to change the interpretation of this value. ${ }^{40}$ Finally, LDL was used as a marker of dyslipidemia in this study; others have reported a link between BMI and high LDL. ${ }^{41}$

Our analysis did not account for several factors that may have influenced risk of adult CVD risk factor levels, including the wide range of ages in the original Heartwatch study (5-15 years) $;^{13}$ and the years between the original Heartwatch study and the follow-up study, during which other risk factors or factors mitigating risk may have influenced or confounded the relationship between childhood BMI, adult BMI, and risk of CVD. A review by Reilly et al. has found evidence to suggest that early childhood BMI does not track to adult BMI as closely as adolescent BMI does; ${ }^{6}$ this is supported by our finding that the BMI of children 12 years old and older had a tighter correlation to adult BMI compared to the BMI of children 9 years old and younger. However, the interval between key visits (1982 and 2008-2009) did not vary greatly among subjects, suggesting that the effects of time within our study population would have been relatively consistent across participants.

Our study is also limited by the lack of heterogeneity in racial or ethnic background of study participants. As such, we cannot generalize our findings to other populations, and further work in this area is needed. Nonetheless, this study provided a rare opportunity to follow up on a cohort assembled in childhood with detailed data related to BMI and health indicators, and to examine the long-term CVD-related consequences of childhood overweight. 
Our findings show strong associations for adult BMI with adult early CVD, and other factors including childhood BMI were not significantly associated with CVD risk factors when accounting for age, gender, and current BMI. Future research is needed to better understand the effect of timing of overweight on health outcomes throughout the lifespan.

\section{Acknowledgements}

We thank the late George Griese, MD for his foresight in establishing a longitudinal cohort 30 years ago. We also thank the staff of the Research Studies Unit, Epidemiology Research Center, Marshfield Clinic Research Foundation, for their dedication. Lastly, we thank the members of the Heartwatch Cohort who participated in this study.

\section{References}

1. Ogden CL, Flegal KM, Carroll MD, Johnson CL. Prevalence and trends in overweight among US children and adolescents, 1999-2000. Journal of the American Medical Association. 2002;288:1728-1732.

2. Ogden CL, Carroll MD, Kit BK, Flegal KM. Prevalence of obesity and trends in body mass index among US children and adolescents, 1999-2010. JAMA. 2012;307(5):483-490. Epub 2012/01/19.

3. Juhola J, Magnussen CG, Viikari JS, Kahonen M, HutriKahonen N, Jula A, et al. Tracking of serum lipid levels, blood pressure, and body mass index from childhood to adulthood: the Cardiovascular Risk in Young Finns Study. J Pediatr. 2011;159(4):584-590. Epub 2011/04/26.

4. Raitakari OT, Juonala M, Kähönen M, Taittonen L, Laitinen T, Mäki-Torkko N, et al. Cardiovascular risk factors in childhood and carotid artery intima-media thickness in adulthood. Journal of the American Medical Association. 2003;290:2277-2283.

5. Li S, Chen W, Srinivasan SR, Bond MG, Tang R, Urbina EM, et al. Childhood cardiovascular risk factors and carotid vascular changes in adulthood: the Bogalusa Heart Study. Journal of the American Medical Association. 2003;290(17):2271-2276.

6. Reilly JJ, Methven E, McDowell ZC, Hacking B, Alexander D, Stewart L, et al. Health consequences of obesity. Arch Dis Child. 2003;88:748-752.

7. Freedman DS, Dietz WH, Tang R, Mensah GA, Bond MG, Urbina EM, et al. The relation of obesity throughout life to carotid intima-media thickness in adulthood: the Bogalusa Heart Study. Int J Obes Relat Metab Disord. 2004;28(1): 159-166.

8. Ben-Shlomo Y, Kuh D. A life course approach to chronic disease epidemiology: conceptual models, empirical challenges and interdisciplinary perspectives. Int J Epidemiol. 2002;31(2):285-293.

9. McDermott MM, Liu K, Criqui MH, Ruth K, Goff D, Saad MF, et al. Ankle-brachial index and subclinical cardiac and carotid disease: the multi-ethnic study of atherosclerosis. Am J Epidemiol. 2005;162(1):33-41. Epub 2005/06/18.

10. Zheng ZJ, Sharrett AR, Chambless LE, Rosamond WD, Nieto FJ, Sheps DS, et al. Associations of ankle-brachial index with clinical coronary heart disease, stroke, and preclinical carotid and popliteal atherosclerosis: the Atherosclerosis Risk in Communities (ARIC) Study. Atherosclerosis. 1997;131(1):115-125.

11. Bots ML, Hofman A, Grobbee DE. Common carotid intimamedia thickness and lower extremity arterial atherosclerosis. The Rotterdam Study. Arterioscler Thromb Vasc Biol. 1994;14(12):1885-1891.
12. Caruana MF, Bradbury AW, Adam DJ. The validity, reliability, reproducibility and extended utility of ankle to brachial pressure index in current vascular surgical practice. Eur J Vasc Endovasc Surg. 2005;29(5):443-451.

13. DeStefano F, Berg RL, Griese GG. Determinants of serum lipid and lipoprotein concentrations in children. Epidemiology. 1995;6(4):446-449.

14. A Training Manual for Height and Weight Assessment. Little Rock, AR: Arkansas Department of Health/Arkansas Department of Education/Arkansas Center for Health Improvement, 2007.

15. Practical guide to identification, evaluation and treatment of overweight and obesity in adults. Bethesda, Maryland: National Institutes of Health, 2000.

16. Healthy Weight: Assessing Your Weight. [Web page] Atlanta, GA: Centers for Disease Control and Prevention; 2011 [cited 2012 May 23]; Available from: http://www.cdc.gov/ healthyweight/assessing/bmi/adult_bmi/index.html.

17. Anthropometric Standardization Reference Manual. Champaign, IL: Human Kinetics Books; 1988.

18. Davis BR, Cutler JA, Gordon DJ, Furberg CD, J. T. Wright J, Cushman WC, et al. Rationale and design for the Antihypertensive and Lipid Lowering Treatment to Prevent Heart Attack Trial (ALLHAT). ALLHAT Research Group. Am J Hypertens. 1996;9(4 part 1):342-360.

19. Understanding Blood Pressure Readings. Dallas, TX2012 [updated April 4, 2012; cited 2012 June 25]; Available from: http://www.heart.org/HEARTORG/Conditions/ HighBloodPressure/AboutHighBloodPressure/ Understanding-Blood-Pressure-Readings_UCM_301764_ Article.jsp.

20. McDermott MM, Criqui MH, Liu K, Guralnik JM, Greenland P, Martin GJ, et al. Lower ankle/brachial index, as calculated by averaging the dorsalis pedis and posterior tibial arterial pressures, and association with leg functioning in peripheral arterial disease. J Vasc Surg. 2000;32(6):1164-1171. Epub 2000/12/07.

21. Resnick HE, Lindsay RS, McDermott MM, Devereux RB, Jones KL, Fabsitz RR, et al. Relationship of high and low ankle brachial index to all-cause and cardiovascular disease mortality: the Strong Heart Study. Circulation. 2004;109(6):733-739. Epub 2004/02/19.

22. Third report of the National Cholesterol Education Program (NCEP) Expert Panel on detection, evaluation, and treatment of high blood cholesterol in adults (Adult Treatment Panel III). Bethesda, MD: National Institutes of Health, 2001.

23. McDowell MA, Fryar CD, Hirsch R, Ogden CL. Anthropometric reference data for children and adults: US Population, 1999-2002. Hyattsville, Maryland: CDC/National Center for Health Statistics, 2005.

24. Cole TJ, Green PJ. Smoothing reference centile curves: the LMS method and penalized likelihood. Stat Med. 1992;11(10):1305-1319.

25. About BMI for Children and Teens. Atlanta, GA: Centers for Disease Control and Prevention; 2011 [cited 2012 April 4]; Available from: http:/www.cdc.gov/healthyweight/assessing/ bmi/childrens bmi/about childrens bmi.html.

26. Freedman DS, Khan LK, Serdula MK, Dietz WH, Srinivasan SR, Berenson GS. The relation of childhood BMI to adult adiposity: the Bogalusa Heart Study. Pediatrics. 2005;115(22):22-27.

27. Lloyd LJ, Langley-Evans SC, McMullen S. Childhood obesity and adult cardiovascular disease risk: a systematic review. Int J Obes. 2010;34(1):18-28. Epub 2009/05/13.

28. Juonala M, Magnussen CG, Berenson GS, Venn A, Burns TL, Sabin MA, et al. Childhood adiposity, adult adiposity, and cardiovascular risk factors. N Engl J Med. 2011;365:1876-1885. 
29. Whitaker RC, Wright JA, Pepe MS, Seidel KD, Dietz WH. Predicting obesity in young adulthood from childhood and parental obesity. N Engl J Med. 1997;337(13):869-873.

30. Serdula MK, Ivery D, Coates RJ, Freedman DS, Williamson DF, Byers T. Do obese children become obese adults? A review of the literature. Preventative Medicine. 1993;22(2):167-177.

31. Greenlee RT. Measuring disease frequency in the Marshfield Epidemiologic Study Area (MESA). Clin Med Res. 2003;1(4):273-280.

32. Greenlee RT, Naleway AL, Vidaillet H. Incidence of myocardial infarction in a general population: the Marshfield Epidemiologic Study Area. Wis Med J. 2002;101(7):46-52.

33. Heald CL, Fowkes FGR, Murray GD, Price JF. Risk of mortality and cardiovascular disease associated with the ankle-brachial index: Systematic review. Atherosclerosis. 2006;189(1):61-69.

34. Al-Qaisi M, Nott DM, King DH, Kaddoura S. Ankle Brachial Pressure Index (ABPI): an update for practitioners. Vascular Health and Risk Management. 2009;5:833-841.

35. Espinola-Klein C, Rupprecht HJ, Bickel C, Lackner K, Savvidis S, Messow CM, et al. Different calculations of ankle-brachial index and their impact on cardiovascular risk prediction. Circulation. 2008;118(9):961-967. Epub 2008/08/14

36. Fowkes FG, Murray GD, Butcher I, Heald CL, Lee RJ, Chambless LE, et al. Ankle brachial index combined with Framingham Risk Score to predict cardiovascular events and mortality: a meta-analysis. JAMA. 2008;300(2):197-208. Epub 2008/07/10.

37. Grenon SM, Gagnon J, Hsiang Y. Ankle-brachial index for assessment of peripheral artery disease. N Engl J Med. 2009;361:e40.

38. Male S, Coull A, Murphy-Black T. Preliminary study to investigate the normal range of Ankle Brachial Pressure Index in young adults. J Clin Nurs. 2006;16:1878-1885.

39. Kuczmarski RJ, Ogden CL, Guo SS, Grummer-Strawn LM, Flegal KM, Mei Z, et al. 2000 CDC growth charts for the United States: methods and development. Atlanta, GA: Centers for Disease Control/National Center for Health Statistics, 2002.

40. Ebbeling CB, Ludwig DS. Tracking pediatric obesity: an index of uncertainty? Journal of the American Medical Association. 2008;299(20):2442-2443.

41. Janssen I, Katzmarzyk PT, Srinivasan SR, Chen W, Malina RM, Bouchard C, et al. Utility of childhood BMI in the prediction of adulthood disease: comparison of national and international references. Obes Res. 2005;13(6):1106-1115.

\section{Author Affiliations}

M.E. Sundaram ${ }^{* 1}$; R.L. Berg"; C. Economos",

L.A. Coleman

*Department of Environmental Health Sciences, University of Minnesota, Minneapolis, MN

${ }^{*}$ Marshfield Clinic Research Foundation, Marshfield, WI

Tufts Friedman School of Nutrition Science and Policy,

Boston, MA

${ }^{*}$ Abbott Nutrition, Columbus, $\mathrm{OH}$

${ }^{1}$ At the time the study was conducted, M.E. Sundaram and L.A. Coleman were employees of Marshfield Clinic

Research Foundation. 